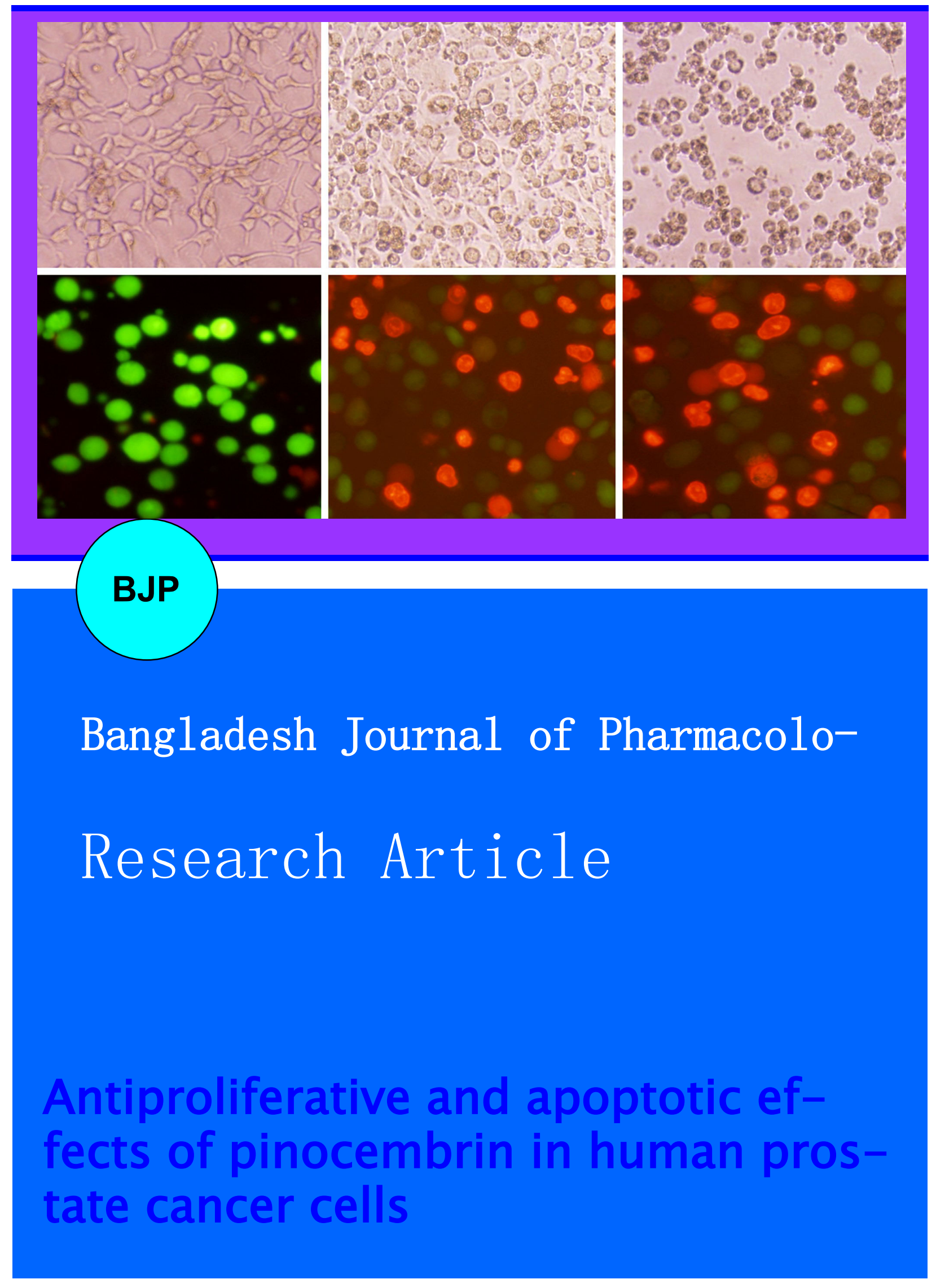




\section{Antiproliferative and apoptotic effects of pinocembrin in human prostate cancer cells}

\section{Zhenyu Chen', Azhar Rasul1, 2, Chaoyue Zhao', Faya Martin Millimouno², Ichiro Tsuji3, Takaki Yamamura4, Rehana Iqbal5, Mahadev Malhi'², Xiaomeng Li² and Jiang Li'}

${ }^{1}$ Dental Hospital, Jilin University, Changchun 130041; ${ }^{2}$ The Key Laboratory of Molecular Epigenetics of MOE, Institute of Genetics and Cytology, School of Life Sciences, Northeast Normal University, Changchun 130024, China; ${ }^{3}$ Department of Public Health, Tohoku University, Sendai 980-8576, Japan; ${ }^{4}$ Food and Nutrition, Morioka College, Iwate, Japan; ${ }^{5}$ Institute of Pure and Applied Biology, Bahauddin Zakariya University, Multan 60800, Pakistan.

\begin{tabular}{|c|c|}
\hline \multicolumn{2}{|l|}{ Article Info } \\
\hline Received: & 30 April 2013 \\
\hline Accepted: & 9 May 2013 \\
\hline Available Online: & 20 May 2013 \\
\hline \multicolumn{2}{|c|}{ DOI: 10.3329/bjp.v8i3.14795 } \\
\hline \multicolumn{2}{|c|}{$\begin{array}{l}\text { Cite this article: } \\
\text { Chen Z, Rasul A, Zhao C, Millimouno } \\
\text { FM, Tsuji I, Yamamura T, Iqbal R, } \\
\text { Malhi M, Li X, Li J. Anti-proliferative } \\
\text { and apoptotic effects of pinocembrin } \\
\text { in human prostate cancer cells. Bang- } \\
\text { ladesh J Pharmacol. 2013; 8: 255-62. }\end{array}$} \\
\hline
\end{tabular}

\begin{abstract}
Pinocembrin, (5, 7-dihydroxyflavanone), has been shown to possess anticancer activity against various cancer cells. However, its effect against prostate cancer cells remained enigmatic. In this study, for the first time, we investigated whether pinocembrin could inhibit growth of human prostate cancer cells. MTT assay and flow cytometric analysis were performed to examine the effects of pinocembrin on cell proliferation, cell cycle, and apoptosis. The results revealed that pinocembrin attenuated the cell viability of both androgen-sensitive (LNCaP) as well as androgen-independent (PC3 and DU-145) prostate cancer cell lines, with different p53 status. Further characterization showed that pinocembrin markedly induced apoptosis of LNCaP cells and arrested cell cycle at $\mathrm{S}$ and G2/M phase and involved in the dissipation of mitochondrial membrane potential before culminating in apoptosis in pinocembrin-treated $\mathrm{LNCaP}$ cells. These in vitro results suggested that pinocembrin should be further examined for in vivo activity in human prostate cancer.
\end{abstract}

\section{Introduction}

Plants provide many promising sources of potential anticancer agents and several lead structures in the past decades such as paclitaxel, camptothecin, vinca alkaloids, and etoposide have potential application in cancer chemotherapy, therefore, plants are considered as one of the most vital sources for the development of novel anti-cancer drugs (Amin et al., 2009; Cragg and Newman, 2005). Extensive researches have been carried out on the phytochemicals, which belong to one vital class of nutraceuticals found in plants, for their healthpromoting potential. Pinocembrin is one of the most important phytochemicals among flavonoids, with antiinflammatory, antimicrobial and anti-oxidants properties (Estevinho et al., 2008; Feng et al., 2012; Kumar et al., 2007). Mainly pinocembrin was isolated from aerial parts of Flourensia oolepis S.F. Blake (Asteraceae) (Diaz Napal et al., 2009) and honey (Jaganathan and Mandal, 2009). Further, pinocembrin being a flavonoid natural compound have been found in fruits, vegetables, nuts, seeds, herbs, spices, stems, flowers, teas, and red wines (Jiang and Morgan, 2004; Miyahisa et al., 2006). Furthermore, pinocembrin has antiproliferative effect and induced apoptosis in cancer cells such as colon cancer (Kumar et al., 2007; Pan et al., 2011; Zizic et al., 2013) and leukemia (Hsu et al., 2010; Salahdeen and Murtala, 2012). However, the cytotoxic effects of pinocembrin on prostate cancer and its mechanism were still unknown.

Prostate cancer is an increasingly common and potentially lethal malignancy. It is the second leading 
cause of cancer-related deaths among men in the United States, with similar trends in many western countries (Jemal et al., 2010). Prevailing treatment options have limited therapeutic success in human prostate cancer, therefore, there is considerable emphasis on identifying novel natural products that selectively induce apoptosis and growth arrest in prostate cancer cells without cytotoxic effects in normal cells (Tsao et al., 2004). In the last few decades, several natural compounds have shown a great promise in treatment of cancer and prevention of metastasis; most of the researchers are interested in and are focusing on finding a cure for cancer and several published reports have identified numerous dietary and botanical natural compounds that have chemopreventive potential (Rasul et al., 2013; Rasul et al., 2012a; Rasul et al., 2012c). Therefore, novel therapeutic agents and treatment approaches are desired to improve the clinical outcome. For this purpose, Therefore, we investigated whether pinocembrin could inhibit growth of both androgensensitive (LNCaP) as well as androgen-independent (PC3 and DU-145) human prostate cancer cell lines, with different p53 status. Pinocembrin showed potent anti-proliferative effect against prostate cancer cells. Further characterization showed that pinocembrin effectively inhibited the proliferation of $\mathrm{LNCaP}$ cells through arresting cell cycle at S and G2/M phases and induction of apoptosis.

\section{Material and Methods}

\section{Chemical and reagents}

Pinocembrin (Figure 1) was purchased from National Institute of Food and Drug Control (Beijing, China). Fetal bovine serum was purchased from Hangzhou Sijiqing Biological Engineering Materials Co., Ltd. DMEM, MTT [3'-(4,5-dimethyl-thiazol-2-yl)-2,5diphenyl tetrazolium bromide], propidium iodide (PI) and dimethyl sulfoxide (DMSO) were purchased from Sigma Chemical Company (St. Louis, USA). Annexin VFITC Apoptosis Detection Kit was purchased from Beyotime Institute of Biotechnology (Shanghai, China). Rho-123 was purchased from Eugene Co. (Oregon, U.S.A.).

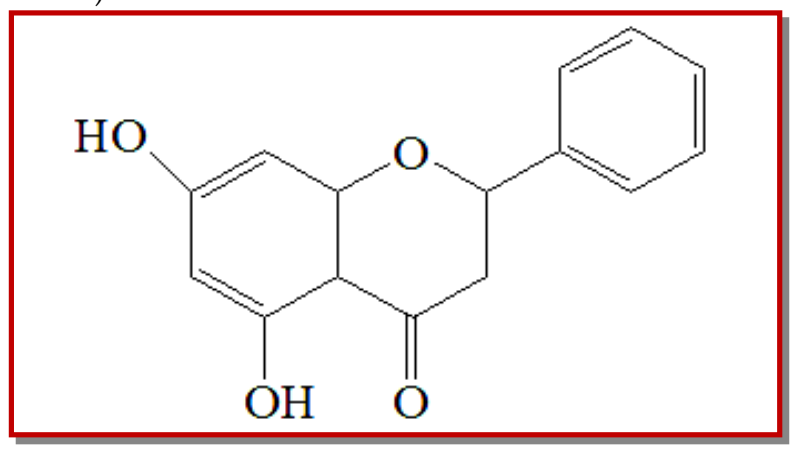

Figure 1: Structure of pinocembrin

\section{Cell culture}

Human prostate cancer LNCaP cells were propagated in DMEM and T-medium (1:1) nutrients mixture supplemented with $10 \%$ FBS and antibiotics at $37^{\circ} \mathrm{C}$ in a humidified atmosphere with $5 \% \mathrm{CO}_{2}$ and $95 \%$ air. Cells were seeded in $10 \mathrm{~cm}$ culture dish and allowed to grow to approximately $70 \%$ confluence before experimentation.

\section{Cell proliferation assay}

The cytotoxic effects of the pinocembrin on the cells were determined by MTT assay as described previously (Rasul et al., 2011a; Rasul et al., 2011b). Briefly, LNCaP cells were seeded at a density of $1 \times 10^{4}$ cells per well in 96-well plates and were allowed to grow overnight. Cells were incubated with $100 \mu \mathrm{L}$ of complete culture medium containing $0,25,50,100,150$, and $200 \mu \mathrm{M}$ of pinocembrin. After incubation for 24 hours, growth of cells was determined by adding $10 \mu \mathrm{L}$ MTT $(5 \mathrm{mg} / \mathrm{mL}$ in phosphate buffered saline) to each well and incubated for 4 hours. After removal of the medium, $150 \mu \mathrm{L}$ DMSO was added to each well and shaken carefully. The absorbance was read at a wavelength of $570 \mathrm{~nm}$ in a plate reader (ELX 800, BIO-TEK Instruments Inc.). The growth curve was plotted against mean values which were calculated using the following equation:

$\mathrm{I} \%=\left[\mathrm{A}_{570}(\right.$ control $)-\mathrm{A}_{570}($ treated $\left.)\right] / \mathrm{A}_{570}($ control $) \times 100$

\section{Flow cytometric analysis of cell cycle}

For cell analysis, LNCaP cells were seeded in 12-well plates and then treated with 100 and $150 \mu \mathrm{M}$ of pinocembrin for 24 hours. After treatments, the percentages of cells in the different phases of cell cycle were evaluated by determining the DNA content after propidium iodide (PI) staining (Rasul et al., 2012b). Briefly, cells were washed with PBS, trypsinized and centrifuged at $1,000 \mathrm{rpm}$ at $4^{\circ} \mathrm{C}$ for $5 \mathrm{~min}$. Pellets were fixed overnight in $70 \%$ cold ethanol. After fixation, cells were washed twice with PBS and incubated in PBS containing RNase $(1 \mathrm{mg} / \mathrm{mL})$ for $10 \mathrm{~min}$ at room temperature. Finally, samples were stained with propidium iodide $(1 \mathrm{mg} / \mathrm{mL})$ for $30 \mathrm{~min}$ at $4^{\circ} \mathrm{C}$. Data acquisition was done by flow cytometry (EPICSXL-MCL, Beckman Coulter, US) using Cell Quest software.

\section{Flow cytometric determination of apoptosis}

The apoptotic rate of $\mathrm{LNCaP}$ cells was examined by flow cytometry using annexin V-FITC/PI staining. Briefly, LNCaP cells were cultured in 6-well plates and allowed to attach overnight. Cells were treated with 100 and $150 \mu \mathrm{M}$ of pinocembrin for 24 hours. Then cells were collected, washed and resuspended in PBS. Apoptotic cell death was measured by double staining annexin V-FITC and PI using the annexin V-FITC apoptosis detection kit (Beyotime Biotechnology Shanghai, 


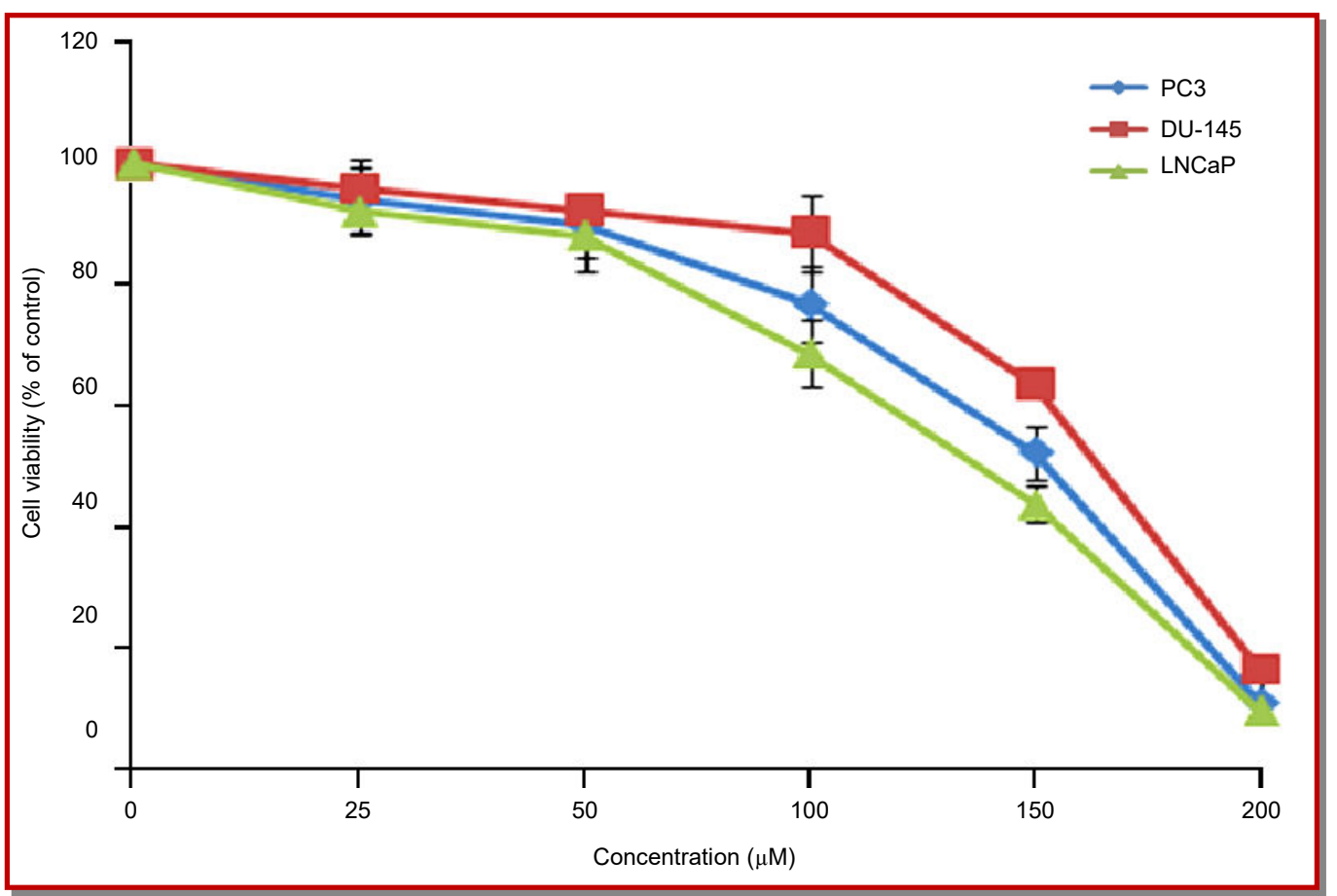

Figure 2: Pinocembrin inhibited the cell growth and induced cell death in prostate cancer cells. LNCaP, PC-3 and DU-145 cells were treated with indicated doses of pinocembrin for 24 hours and cell viability was measured by MTT assay. Data are expressed as Mean $\pm \mathrm{SD}(\mathrm{n}=3)$

China) according to the manufacturer's instructions. Flow cytometric analysis was performed immediately after staining. Data acquisition and analysis were performed by flow cytometry using Cell Quest software.

\section{Flow cytometric determination of mitochondrial mem-} brane potential $\left(\Delta \Psi_{m}\right)$

To probe the changes in $\Delta \Psi_{\mathrm{m}}$, PC3 cells were stained with rhodamine $123(1 \mu \mathrm{M})$ after treatment of 100 and $150 \mu \mathrm{M}$ of pinocembrin for 24 hours with control group. The fluorescence of rhodamine 123 was measured by flow cytometry with excitation and emission wavelengths of 488 and $530 \mathrm{~nm}$.

\section{Statistical analysis of data}

For the statistical analysis of data, comparisons between results from different groups were analyzed with SPSS for Window Version 15.0. $\mathrm{p}<0.05$ value was defined as statistically significant. All experiments were repeated at least three times.

\section{Results and Discussion}

The investigation was started with screening of natural compounds against androgen-sensitive (LNCaP) as well as androgen-independent (PC3 and DU-145) human prostate cancer cell lines, with different p53 status. We found that pinocembrin exhibited cytotoxic effects on the growth of both androgen-responsive
(LNCaP) as well as androgen-resistant (PC3 and DU145) human prostate cancer. Pinocembrin is a natural compound that belongs to a flavonoid family. We examined the effects of pinocembrin on the growth of LNCaP human prostate cancer cells by quantifying the viable cells using MTT assay. Pinocembrin attenuated the growth of LNCaP human prostate cancer cells in a dose-dependent manner (Figure 2). Morphological changes were observed under phase contrast microscopy after treating cells with 100 and $150 \mu \mathrm{M}$ of pinocembrin. There was a significant decrease in the number of LNCaP cells treated with pinocembrin as compared to the control group. Furthermore, the cells become round-shaped and poorly adhered to the cultured plates while the control group cells showed a typical polygonal and cobblestone monolayer appearance and remained firmly attached to cultured plates (Figure 3). The results revealed that pinocembrin induced growth inhibition of LNCaP cells, in addition to other type of cancer cells previously reported including colon cancer (Kumar et al., 2007; Pan et al., 2011; Zizic et al., 2013) and leukemia (Hsu et al., 2010; Salahdeen and Murtala, 2012).

There are several mechanisms which control the cell cycle to ensure the correct cell division. It is well known that progression of cell cycle is maintained by different check points in normal cells and the transition from one cell cycle phase to another occurs in an orderly fashion. In cancerous cells, some basic modifications occurred in the genetic control of cell division, resulting in an 


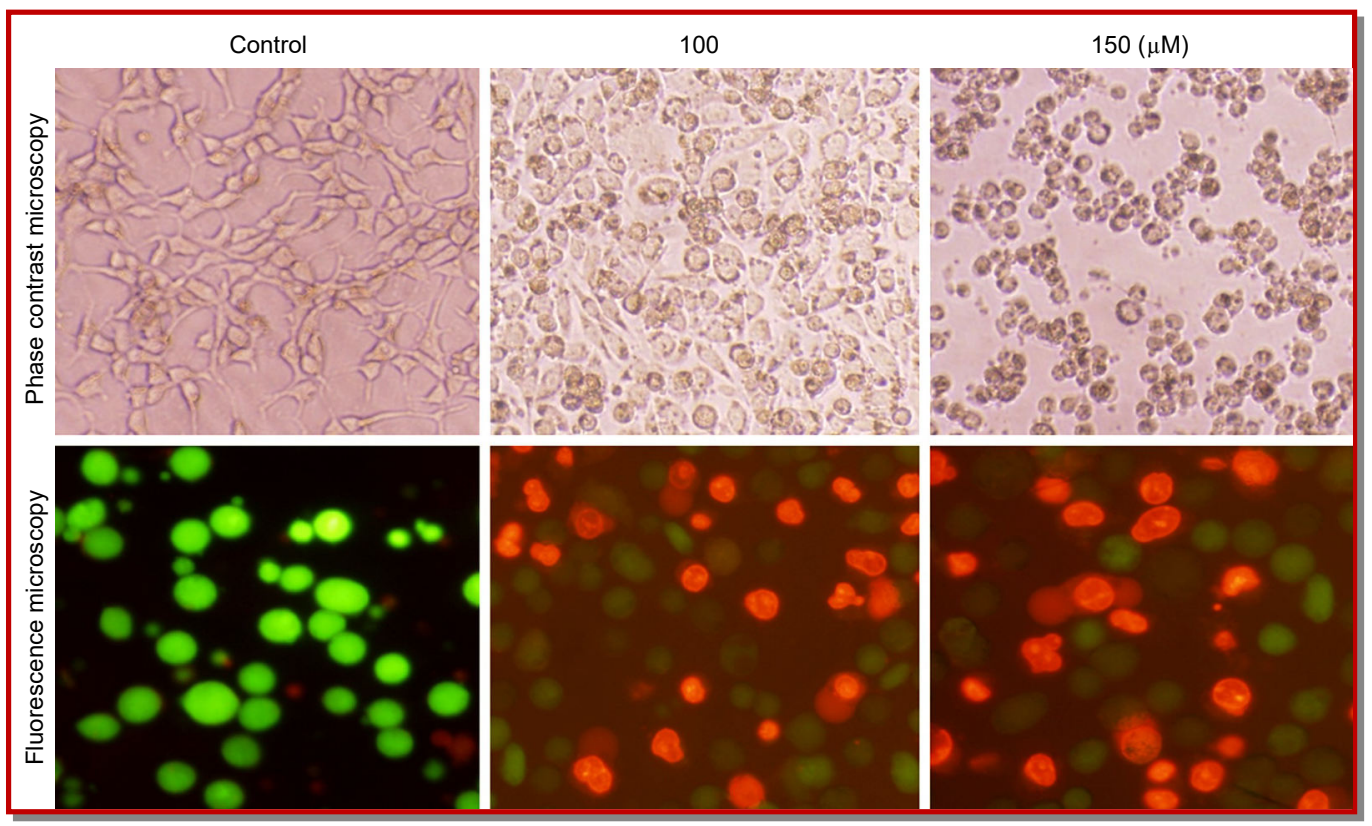

Figure 3: Morphological changes in human prostate cancer LNCaP cells were observed under phase contrast and fluorescence microscopy after treatment with 0,100 and $150 \mu \mathrm{M}$ of pinocembrin for 24 hours

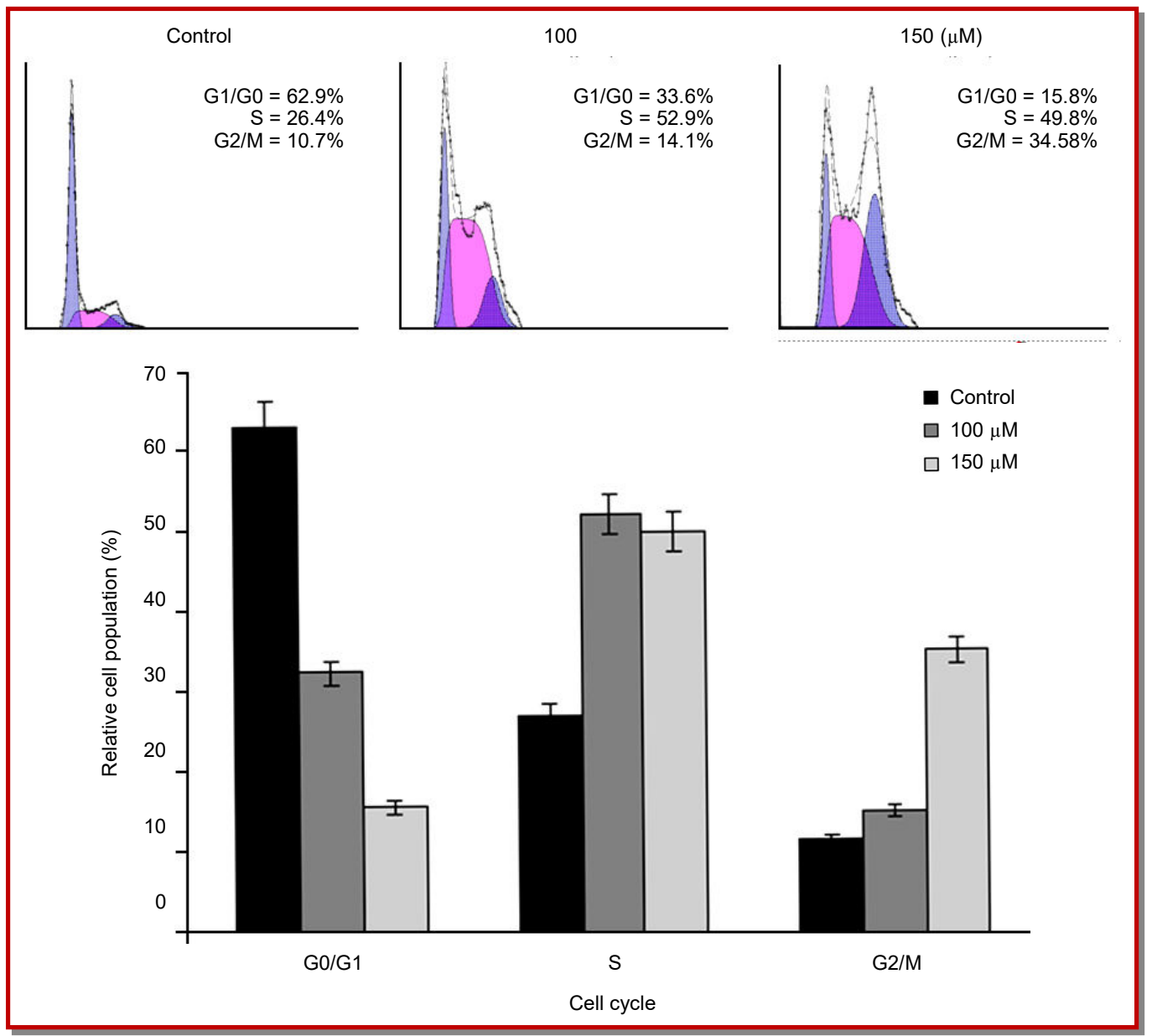

Figure 4: Flow cytometry analysis of cell cycle phase distribution in LNCaP cells treated with 100 and $150 \mu \mathrm{M}$ pinocembrin for 24 hours. The data shown are representative of two independent experiments with the similar results. a $<<0.05$ and b $<<0.01$ compared with the control 


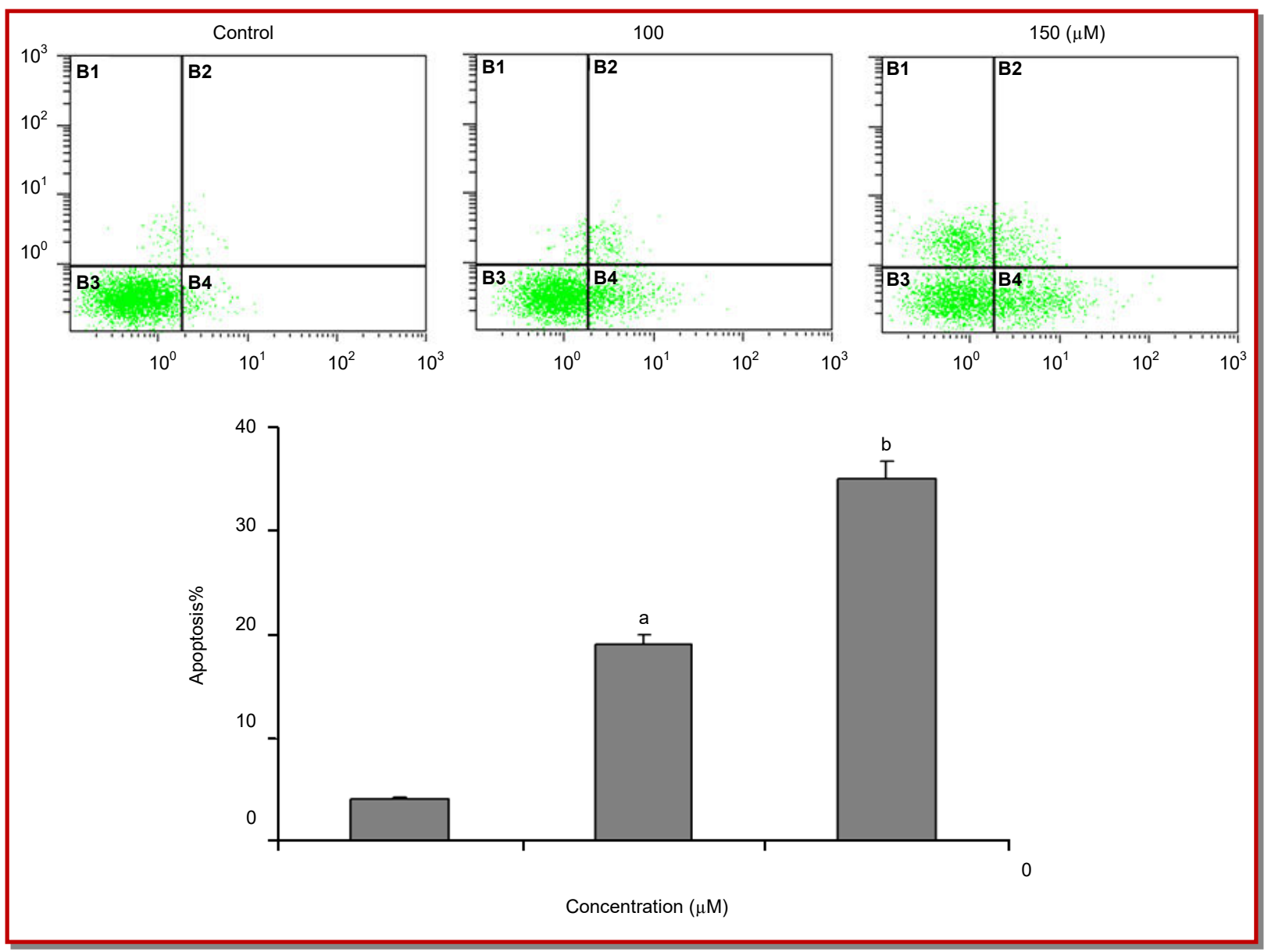

Figure 5: Apoptosis induced by pinocembrin in LNCaP cells. LNCaP cells were treated with 100 and $150 \mu \mathrm{M}$ of pinocembrin for 24 hours. Then cells were stained with FITC-conjugated Annexin V and PI for flow cytometric analysis. The flow cytometry profile represents Annexin V-FITC staining in $x$ axis and PI in $y$ axis. The data shown are representative of three independent experiments with the similar results. ${ }^{a} p<0.05$ and ${ }^{b} p<0.01$ compared with the control

uncontrolled cell proliferation. As the deregulation of cell cycle progression is the hallmark of cancer; thereby cell cycle regulation could be a potential and effective strategy for the treatment of cancer (Grana and Reddy, 1995; Vermeulen et al., 2003). Therefore, we analyzed effect of pinocembrin on cell cycle progression of LNCaP cells. It was found that pinocembrin arrested cell cycle at $\mathrm{S}$ and $\mathrm{G} 2 / \mathrm{M}$ phases. The percentage of accumulation of cells in the G2/M phase was increased from $10.7 \%$ in control group to $14.1 \%$, and $34.5 \%$ in the cells treated with 100 and $150 \mu \mathrm{M}$ of pinocembrin respectively while S phase was increased from $26.4 \%$ in control group to 52.6 and $49.8 \%$ respectively for 24 hours (Figure 4). These findings revealed that $S$ and G2/M phase cell cycle arrest was one of the mechanisms through which pinocembrin induces cytotoxicity in LNCaP cells. A number of recent studies have shown that by arresting the cell division at certain checkpoints in the cell cycle, several chemotherapeutic and chemopreventive agents have demonstrated potential anti-proliferative effects (Rasul et al., 2013; Rasul et al., 2012b).
There are various modes of cell death such as apoptosis, autophagy and necrosis (Leist and Jaattela, 2001). Apoptosis is most organized, well fashioned, and systematic mode of cell death, in which cells themselves play an active role in their own death (Elmore, 2007; Hengartner, 2000). The normal cellular signals for regulation of their growth are lost in the cancerous cells due to various mutations, preventing the cells from apoptosis and cell growth to uncontrolled status (Hanahan and Weinberg, 2000). The regulation of apoptosis is, therefore, most important in the treatment of cancer (Fulda, 2010; Lawen, 2003; Reed, 2002). The chemopreventive agents, which can treat the cancer effectively, have potential to restore the natural signaling apoptotic pathway (Reed, 1999). It is well known that various chemopreventive agents cause cell death through induction of apoptosis in different cancer cells (Srivastava and Gupta, 2006; Xu et al., 2009). We studied whether pinocembrin inhibits cell growth in LNCaP cells through the induction of apoptosis. Pinocembrin-induced apoptosis was determined by flow cytometric analysis. 


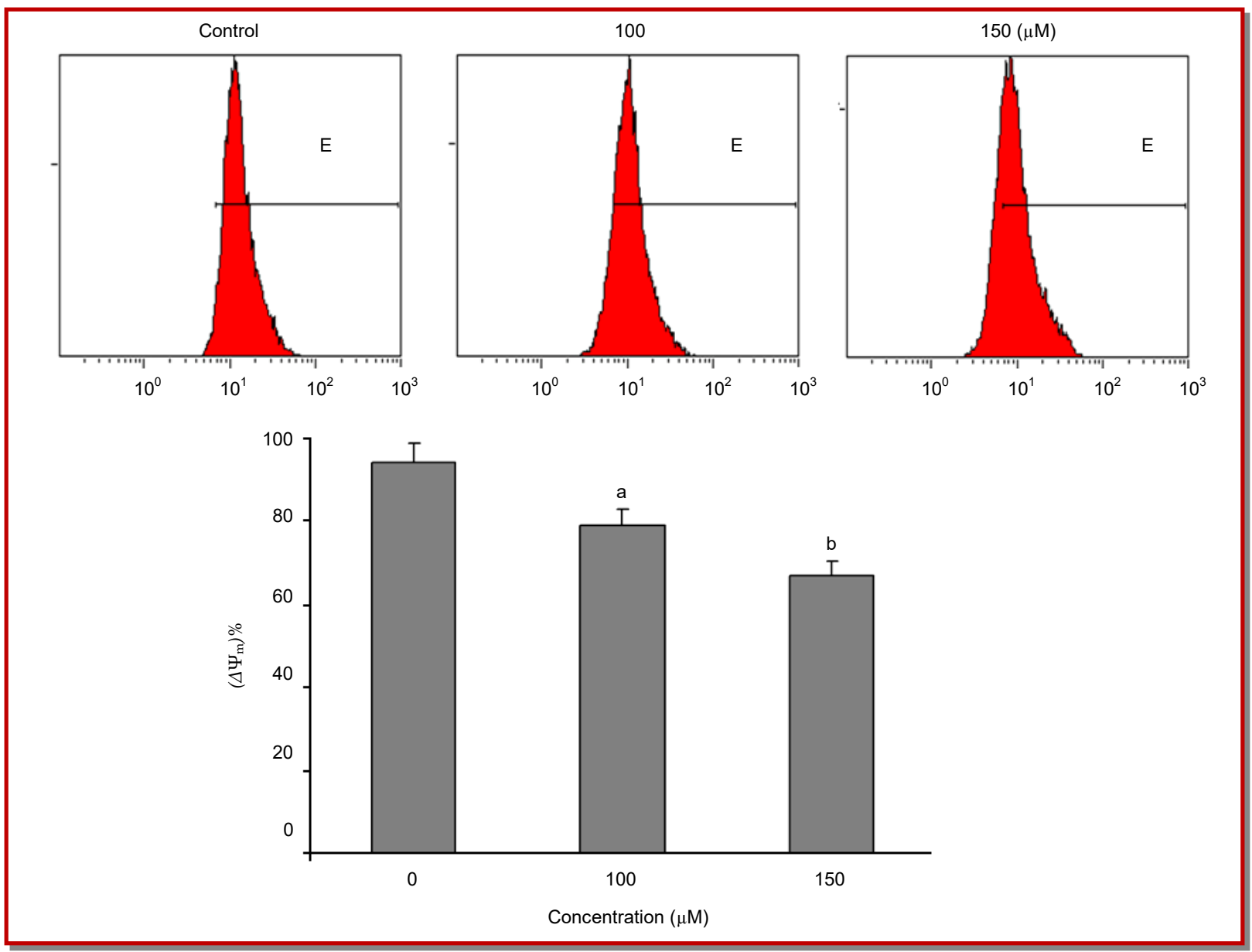

Figure 6: The effects of pinocembrin on mitochondrial transmembrane potential of LNCaP cells were determined by flow cytometry. The values indicate the percentages of rhodamine 123 fluorescence in the LNCaP cells treated without and with 100 and 150 $\mu \mathrm{M}$ of pinocembrin for 24 hours. The data shown are representative of three independent experiments with the similar results. ${ }^{\mathrm{a}} \mathrm{p}<0.05$ and ${ }^{\mathrm{b}} \mathrm{p}<0.01$ compared with the control

For flow cytometric analysis, cells were seeded in the 12 well plates. After incubation of cells without (control) or with pinocembrin for 24 hours, cells were collected in centrifuged tubes and stained with annexin V-FITC and PI double staining as described in material and methods part. The results of flow cytometric analysis showed that rates of apoptosis were $19.2 \pm 2.0 \%$ and $35.4 \pm 2.3 \%$ in the cells treated with 100 and $150 \mu \mathrm{M}$ of pinocembrin respectively for 24 hours as compared to $4.0 \pm 0.5 \%$ in the control cells (Figure 5). Pinocembrininduced apoptosis in LNCaP cells was consistent with previously reported studies in colon cancer (Kumar et al., 2007).

Mitochondria play a fundamental role in the regulation of apoptotic cell death and consist of various proapoptotic proteins and cytochrome $c$. As highlighted earlier, apoptosis involves a dysfunction of mitochondrial membrane integrity, which leads to cell death (Jeong and Seol, 2008). Previously it has been documented that disintegration of the mitochondrial membrane potential and the redistribution of cytochrome $c$ are crucial actions in the apoptotic cascade (Kluck et al., 1997; Wang, 2001). Cytochrome $c$ plays central role in mitochondrial mediated apoptosis. Upon the attenuation of mitochondrial transmembrane potential, Cytochrome $c$ releases from the mitochondria into the cytosol (Kluck et al., 1997). Once released into the cytosol, cytochrome $c$ binds to form an "apoptosome" of Apaf-1, cytochrome $c$, and caspase-9, which subsequently cleaves the effecter caspase-3 (Ricci and Zong, 2006).

The effects of pinocembrin on the mitochondrial membrane potential of LnCaP cells were determined by flow cytometry using rhodamine 123 staining. The rates of depletion of mitochondrial membrane potential were $84.0 \pm 1.3$ and $71.2 \pm 1.7 \%$ in the cells treated with 100 and $150 \mu \mathrm{M}$ of pinocembrin, respectively, for 24 hours as compared to $96.1 \pm 0.4 \%$ in the control group (Figure $6)$. These results are similar with previously reported studies in colon cancer (Kumar et al., 2007). 


\section{Conclusion}

Pinocembrin induced apoptosis of LNCaP human prostate cancer cells accompanied by $\mathrm{S}$ and $\mathrm{G} 2 / \mathrm{M}$ phase cell cycle arrest. Further characterization showed that pinocembrin involved in dissipation of mitochondrial membrane potential before culminating in apoptosis in pinocembrin-treated LNCaP cells.

\section{Acknowledgments}

This study was supported by Ministry of Science and Technology (No. 2010DFA31430), Ministry of Education of China (NCET-10-0316; 101020031), Jilin Provincial Science \& Technology Department (No. YYZX201241, 20070719, and 200905116); Changchun Science \& Technology Department (No. 2011114-11GH29) and National Natural Science Foundation of China (Nos.30871301).

\section{References}

Adams JM, Cory S. The Bcl-2 apoptotic switch in cancer development and therapy. Oncogene 2007; 26: 1324-37.

Amin AR, Kucuk O, Khuri FR, Shin DM. Perspectives for cancer prevention with natural compounds. J Clin Oncol. 2009; 27: 2712-25.

Burlacu A. Regulation of apoptosis by Bcl-2 family proteins. J Cell Mol Med. 2003; 7: 249-57.

Cragg GM, Newman DJ. Plants as a source of anti-cancer agents. J Ethnopharmacol. 2005; 100: 72-79.

Danial NN. BCL-2 family proteins: Critical checkpoints of apoptotic cell death. Clin Cancer Res. 2007; 13: 7254-63.

Diaz Napal GN, Carpinella MC, Palacios SM. Antifeedant activity of ethanolic extract from Flourensia oolepis and isolation of pinocembrin as its active principle compound. Bioresour Technol. 2009; 100: 3669-73.

Elmore S. Apoptosis: A review of programmed cell death. Toxicol Pathol. 2007; 35: 495-516.

Estevinho L, Pereira AP, Moreira L, Dias LG, Pereira E. Antioxidant and antimicrobial effects of phenolic compounds extracts of Northeast Portugal honey. Food Chem Toxicol. 2008; 46: 3774-79.

Feng R, Guo ZK, Yan CM, Li EG, Tan RX, Ge HM. Antiinflammatory flavonoids from Cryptocarya chingii. Phytochemistry 2012; 76: 98-105.

Fulda S. Evasion of apoptosis as a cellular stress response in cancer. Int J Cell Biol. 2010; 2010: 370835.

Grana X, Reddy EP. Cell cycle control in mammalian cells: Role of cyclins, cyclin dependent kinases (CDKs), growth suppressor genes and cyclin-dependent kinase inhibitors (CKIs). Oncogene 1995; 11: 211-19.

Hanahan D, Weinberg RA. The hallmarks of cancer. Cell 2000; 100: $57-70$

Hengartner MO. The biochemistry of apoptosis. Nature 2000;
407: 770-76.

Hsu CL, Yu YS, Yen GC. Anti-cancer effects of Alpinia pricei Hayata roots. J Agric Food Chem. 2010; 58: 2201-08.

Jaganathan SK, Mandal M. Anti-proliferative effects of honey and of its polyphenols: A review. J Biomed Biotechnol. 2009; 2009: 830616.

Jemal A, Siegel R, Xu J, Ward E. Cancer statistics, 2010. CA Cancer J Clin. 2010; 60: 277-300.

Jeong SY, Seol DW. The role of mitochondria in apoptosis. BMB Rep. 2008; 41: 11-22.

Jiang $\mathrm{H}$, Morgan JA. Optimization of an in vivo plant P450 monooxygenase system in Saccharomyces cerevisiae. Biotechnol Bioeng. 2004; 85: 130-137.

Kluck RM, Bossy-Wetzel E, Green DR, Newmeyer DD. The release of cytochrome $\mathrm{c}$ from mitochondria: A primary site for Bcl-2 regulation of apoptosis. Science 1997; 275: 1132-36.

Kumar MA, Nair M, Hema PS, Mohan J, Santhoshkumar TR. Pinocembrin triggers Bax-dependent mitochondrial apoptosis in colon cancer cells. Mol Carcinog. 2007; 46: 231-41.

Lawen A. Apoptosis: An introduction. Bioessays 2003; 25: 88896.

Leist M, Jaattela M. Four deaths and a funeral: From caspases to alternative mechanisms. Nat Rev Mol Cell Biol. 2001; 2: 589-98.

Li L, Yue GG, Lau CB, Sun H, Fung KP, Leung PC, Han Q, Leung PS. Eriocalyxin B induces apoptosis and cell cycle arrest in pancreatic adenocarcinoma cells through caspaseand p53-dependent pathways. Toxicol Appl Pharmacol. 2012; 262: 80-90.

Mallat Z, Tedgui A. Apoptosis in the vasculature: Mechanisms and functional importance. Br J Pharmacol. 2000; 130: 94762 .

Miyahisa I, Funa N, Ohnishi Y, Martens S, Moriguchi T, Horinouchi S. Combinatorial biosynthesis of flavones and flavonols in Escherichia coli. Appl Microbiol Biotechnol. 2006; 71: 53-58.

Pan L, Matthew S, Lantvit DD, Zhang X, Ninh TN, Chai H, Carcache de Blanco EJ, Soejarto DD, Swanson SM, Kinghorn AD. Bioassay-guided isolation of constituents of Piper sarmentosum using a mitochondrial transmembrane potential assay. J Nat Prod. 2011; 74: 2193-99.

Rasul A, Bao R, Malhi M, Zhao B, Tsuji I, Li J, Li X. Induction of apoptosis by costunolide in bladder cancer cells is Mediated through ROS Generation and Mitochondrial dysfunction. Molecules 2013; 18: 1418-33.

Rasul A, Ding C, Li X, Khan M, Yi F, Ali M, Ma T. Dracorhodin perchlorate inhibits $\mathrm{PI} 3 \mathrm{~K} /$ Akt and NF-kappaB activation, up-regulates the expression of p53, and enhances apoptosis. Apoptosis 2012a; 17: 1104-19.

Rasul A, Khan M, Yu B, Ma T, Yang H. Xanthoxyletin, a coumarin induces $\mathrm{S}$ phase arrest and apoptosis in human gastric adenocarcinoma SGC-7901 cells. Asian Pac J Cancer Prev. 2011a; 12: 1219-23.

Rasul A, Song R, Wei W, Nishino Y, Tsuji I, Li X, Li J. 
Tubeimoside- 1 inhibits growth via the induction of cell cycle arrest and apoptosis in human melanoma A375 cells. Bangladesh J Pharmacol. 2012b; 7: 150-56.

Rasul A, Yu B, Yang LF, Ali M, Khan M, Ma T, Yang H. Induction of mitochondria-mediated apoptosis in human gastric adenocarcinoma SGC-7901 cells by kuraridin and Nor-kurarinone isolated from Sophora flavescens. Asian Pac J Cancer Prev. 2011b; 12: 2499-2504.

Rasul A, Yu B, Zhong L, Khan M, Yang H, Ma T. Cytotoxic effect of evodiamine in SGC-7901 human gastric adenocarcinoma cells via simultaneous induction of apoptosis and autophagy. Oncol Rep. 2012c; 27: 1481-87.

Reed JC. Bcl-2 family proteins. Oncogene 1998; 17: 3225-36.

Reed JC. Dysregulation of apoptosis in cancer. J Clin Oncol. 1999; 17: 2941-53.

Reed JC. Apoptosis-based therapies. Nat Rev Drug Discov. 2002; 1: 111-21.

Ricci MS, Zong WX. Chemotherapeutic approaches for targeting cell death pathways. Oncologist 2006; 11: 342-57.

Salahdeen HM, Murtala BA. Vasorelaxant effects of aqueous leaf extract of Tridax procumbens on aortic smooth muscle isolated from the rat. J Smooth Muscle Res. 2012; 48: 37-45.

Srivastava JK, Gupta S. Tocotrienol-rich fraction of palm oil induces cell cycle arrest and apoptosis selectively in human prostate cancer cells. Biochem Biophys Res Commun. 2006; 346: 447-53.

Tsao AS, Kim ES, Hong WK. Chemoprevention of cancer. CA Cancer J Clin. 2004; 54: 150-80.

Vermeulen K, Van Bockstaele DR, Berneman ZN. The cell cycle: A review of regulation, deregulation and therapeutic targets in cancer. Cell Prolif. 2003; 36: 131-49.

Wang X. The expanding role of mitochondria in apoptosis. Genes Dev. 2001; 15: 2922-33.

Xu Y, Chiu JF, He QY, Chen F. Tubeimoside-1 exerts cytotoxicity in HeLa cells through mitochondrial dysfunction and endoplasmic reticulum stress pathways. J Proteome Res. 2009; 8: 1585-93.

Zizic JB, Vukovic NL, Jadranin MB, Andelkovic BD, Tesevic VV, Kacaniova MM, Sukdolak SB, Markovic SD. Chemical composition, cytotoxic and anti-oxidative activities of ethanolic extracts of propolis on HCT-116 cell line. J Sci Food Agric. 2013. 